\title{
Immunoreactivity of MAPK Signaling in a Rat Model of Intrauterine Growth Retardation Induced by Uterine Artery Ligation
}

\author{
MIN SEON CHOI ${ }^{1}$, YOON YOUNG CHUNG ${ }^{2}$, DONG-JOON KIM ${ }^{3}$, SEONG TAECK KIM ${ }^{4}$ and YONG HYUN JUN ${ }^{2}$ \\ ${ }^{1}$ Department of Pediatrics, Chosun University Hospital, Gwang-ju, Republic of Korea; \\ ${ }^{2}$ Department of Anatomy, School of Medicine, Chosun University, Gwang-ju, Republic of Korea; \\ ${ }^{3}$ Department of Anesthesiology and Pain Medicine, Chosun University Hospital, Gwang-ju, Republic of Korea; \\ ${ }^{4}$ Department of Ophthalmology, Chosun University Hospital, Gwang-ju, Republic of Korea
}

\begin{abstract}
Background/Aim: Intrauterine growth retardation (IUGR) causes very low birth weight and is related to the morbidity and mortality of the newborn. In our previous study, expression of brain-derived neurotrophic factor (BDNF) was found reduced in the cerebral cortex and dentate gyrus of fetuses with IUGR. BDNF protected cortical neurons against hypoxic injury via activation of the extracellular signal-related kinase (ERK) pathway. The aim of the current study was to observe the immunoreactivity of ERK in mature neurons and proliferating cells. Materials and Methods: Uterine artery ligation was performed at 17 days of gestation (dg). Rat fetuses were obtained at $21 \mathrm{dg}$ using cesarean section. Fetuses were designated either to the growth retardation $(G R)$ group when removed from the horn with uterine artery ligation, or to the control group when removed from the other horn with the untied artery. Immunohistochemistry was performed with primary antibodies on paraffin-embedded forebrain sections. Results: The density and proportion of cells expressing PCNA, ERK, and phosphate ERK in the subventricular zone (SVZ) was not different between the control and GR group. The density and proportion of NeuN-and phosphate ERK-positive cells in the cerebral parietal cortex was lower in the GR group, compared to the control group. Conclusion: Although IUGR had no effect on the proliferation of cells in the SVZ, it reduced neuronal survival in the cerebral parietal cortex,
\end{abstract}

This article is freely accessible online.

Correspondence to: Department of Plastic and Reconstructive Surgery, Chosun University Hospital, 375 Seosuk-dong, Dong-Gu, Gwangju 501-759, Republic of Korea. Tel: +82 1028862973, Fax: +82 0622341474, e-mail: jyh1483@chosun.ac.kr

Key Words: Hypoxia, ERK, phosphate-ERK, Cortex, SVZ. which was associated with the decrease of pERK-positive cell density and proportion in the cerebral cortex.

Intrauterine growth retardation (IUGR) causes very low birth weight (1) and is related to the morbidity and mortality of newborn infants. A majority of pregnancies with IUGR symptoms result in stillbirth or neonatal death (2). Furthermore, IUGR is generally associated with placental insufficiency (3) and is caused by abnormalities in the umbilical artery (4). The common symptoms in fetuses undergoing placental insufficiency include malnutrition, hypoxemia, and hypoglycemia (5).

The uterine artery ligation animal model, with placental insufficiency and IUGR (6), is a good representation of the human IUGR condition (7). This model has been used to demonstrate metabolic and hemodynamic abnormalities during cardiac (8), vascular (9), and neurological development $(10,11)$. Some studies state that the growth of the majority of infants with IUGR is normalized by the age of 2-3 years $(12,13)$. However, other studies showed that IUGR caused neurological disorders such as cerebral palsy (14), schizophrenia (15), and problems with learning/ memory (16).

IUGR is also associated with neurogenesis, which is a process that encompasses the proliferation, growth, migration, and survival of neuronal cells. The number of neurons was reduced in the hippocampus and cerebellum of postnatal fetuses $(17,18)$. Further, morphological changes were seen during the prenatal period in IUGR fetuses (19) and the neocortical volume was reduced in IUGR neonates (20).

In our previous study (21), cell survival was reduced in the cerebral cortex and dentate gyrus of fetuses with hypoxia. In addition, the expression of brain-derived neurotrophic factor (BDNF) was also decreased in the same regions (21). BDNF plays an important role in neuronal cell proliferation and survival (22). Another study demonstrated 
that BDNF protected cortical neurons against hypoxic injury via activation of the extracellular signal-related kinase (ERK) pathway (23). ERK activation promoted the survival of pheochromocytoma 12 (24) and retinal ganglion cells (25).

The aim of this study was to observe the immunoreactivity of ERK and phosphate-ERK (pERK) in mature neurons and proliferating cells.

\section{Materials and Methods}

Animal surgery. The Chosun University Institutional Animal Care and Use Committee approved all animal experiments (approval number: CIACUC2014-A0026). Sprague-Dawley (SD) rats were supplied from a certified breeder (Damul Laboratory Animals, Republic of Korea). The rats were mated for three days. Female rats were then checked vaginally to determine the pregnancy status. Uterine artery ligation was performed as reported in a previous study (26). Briefly, animals were anesthetized by intramuscular injection with zoletil (10 mg/kg; Virbac, France) and xylazine $(0.15 \mathrm{mg} / \mathrm{kg}$; Bayer, Germany) at 17 days of gestation (dg). After shaving below the umbilicus, we performed a midline incision under aseptic surgical conditions. The uterine horn was found, and the uterine artery at the cervical level was ligated with silk sutures (4/0). After the procedure, the skin on abdominal region was sterilized using povidone-iodine solution (Green Medical, Republic of Korea). All animals were bred in the same environment.

Tissue preparation. At $21 \mathrm{dg}$, we reopened the surgical site of pregnant rats $(n=14)$ and obtained fetuses by cesarean section. Fetuses that were removed from the horn with the artery ligation were designated to the growth retardation (GR) group $(n=45)$, while fetuses that were removed from the other horn with the untied artery served as the control group $(n=47)$. We measured body and brain weights, crown-rump length, and the brain-to-body-weight ratio of both fetus groups. The brains of the fetuses were removed, fixed in $4 \%$ paraformaldehyde (PFA) solution, and washed after two days in distilled water. The brains were dehydrated in a series of graded ethanol and embedded in paraffin. Serial coronal sections were cut at $12 \mu \mathrm{m}$ thickness and mounted on gelatin-coated slides (Fisher Scientific, Pittsburgh, PA, USA).

Immunohistochemistry. The sections were deparaffinized, washed with $0.1 \mathrm{M}$ phosphate buffered saline (PBS; $\mathrm{pH} 7.4$ ), and heated in a microwave for $10 \mathrm{~min}$ with $0.01 \mathrm{M}$ sodium citrate buffer ( $\mathrm{pH}$ 6.0) for antigen retrieval. After cooling for $40 \mathrm{~min}$, the sections were soaked in $0.3 \%$ hydrogen peroxide solution for $20 \mathrm{~min}$ to block endogenous peroxidase. After washing with PBS, sections were then immersed with primary antibody solutions and incubated overnight at $4^{\circ} \mathrm{C}$. The next day, the sections were rinsed with PBS and incubated with the appropriate secondary antibody solutions, which matched the type of primary antibody. The immunoreactivity (IR) of cells in the sections was visualized using an avidin-biotinperoxidase $(\mathrm{ABC})$ detection system (Vectastain $\mathrm{ABC}$ Elite Kit, Vector Laboratories). Counterstaining was performed with thionin. The sections were mounted with PolyMount mounting medium (Polysciences, USA).

The primary antibodies used were as follows: mouse antihexaribonucleotide-binding protein 3 (NeuN, 1:100; Millipore, USA), mouse anti-proliferating cell nuclear antigen (PCNA,
Table I. Body and brain weight and crown-rump length of control and GR groups at 21 days of gestation.

\begin{tabular}{lcc}
\hline & Control $(\mathrm{n}=47)$ & GR $(\mathrm{n}=45)$ \\
\hline Body weight, g & $4.857 \pm 1.012$ & $2.428 \pm 0.941^{*}$ \\
Brain weight, g & $0.308 \pm 0.018$ & $0.233 \pm 0.032$ \\
Crown-rump length, cm & $2.2 \pm 0.15$ & $2.1 \pm 0.18$ \\
Brain:body ratio & $0.063 \pm 0.018$ & $0.096 \pm 0.034^{*}$ \\
\hline
\end{tabular}

Values are expressed as the mean \pm SEM. ${ }^{*} p<0.05$.

1:1,000; Sigma-Aldrich, USA), rabbit anti-ERK (1:50; Santa Cruz, USA), and goat anti-p-ERK (1:50; Santa Cruz, USA).

Quantification. Immunoreactivity of the sections was visualized using a light microscope (Olympus BX41, USA) connected to a digital CCD camera. Coronal sections separated by a distance of $240 \mu \mathrm{m}$ were obtained from each animal. The density of cells expressing NeuN, PCNA, ERK, and pERK was determined by counting the number of immunoreactive cells in a defined field (objective: 400x), as described previously (27), in five randomly selected areas in the granular layer of cerebral parietal cortex and SVZ. The proportion of these cells was expressed as a percentage of the total number of cells in each region. IR cells were manually counted using double blind protocols.

Statistical analysis. All data were analyzed using Statistical Package for Social Sciences (Information Analysis Systems, SPSS, USA). All measurements were compared between the control and GR groups using Student's $t$-tests. The statistical significance was set at $p<0.05$.

\section{Results}

At $21 \mathrm{dg}$, body and brain weights in the GR group were decreased relative to those of the control group. The ratio of brain-to-body weight in GR fetuses was also increased relative to that of controls (Table I). At $21 \mathrm{dg}$, the density and proportion of PCNA-IR cells in the subventricular zone (SVZ) was the same in the control and GR groups (Figure 1). The density and proportion of NeuN-IR cells in the cerebral parietal cortex was lower in the GR group, in comparison to the control group (Figure 2). There were no differences in the density and proportion of ERK-IR cells in the cerebral cortex and SVZ, between the control and GR groups (Figure 3 ). Although the density and proportion of pERK-IR cells of the GR group did not differ from the control group in the SVZ, it decreased in the cerebral parietal cortex (Figure 4).

\section{Discussion}

Unilateral artery ligation was used to induce hypoxia in pregnant rats at $17 \mathrm{dg}$. This time-point is the onset of the period of rapid fetal growth and matches the third trimester 

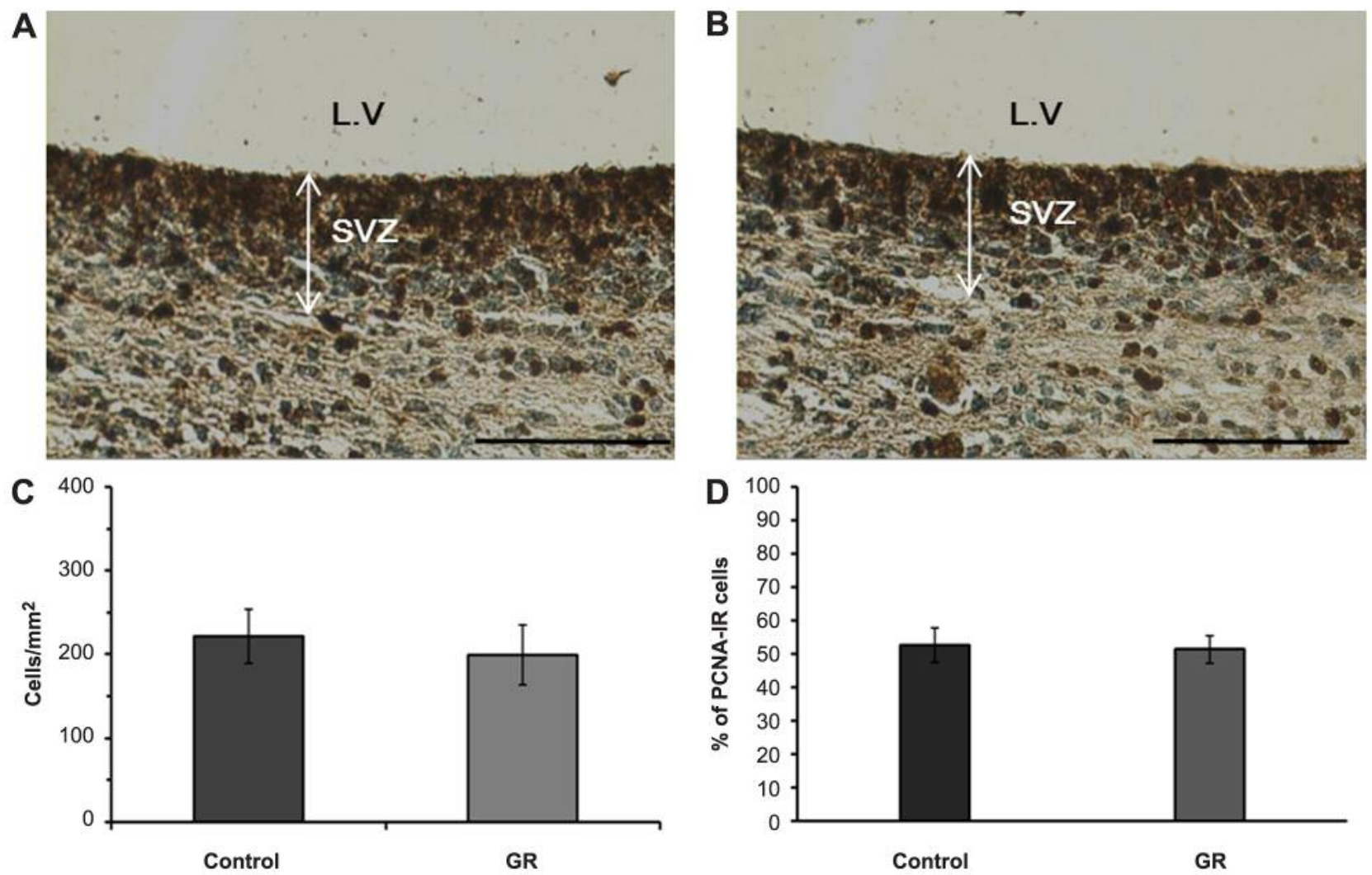

Figure 1. Representative photomicrographs of PCNA-IR cells in the SVZ. PCNA-IR cells were observed as dark-brown color in the control (A) and GR (B) groups. Scale bars=100 $\mu \mathrm{m}$. The density (C) and proportion (D) of PCNA-IR cells in the SVZ of control and GR fetuses at 21 days of gestation. No significant difference in the density and proportion of IR cells was observed between the two groups. Values are expressed as the mean \pm SEM.

in human pregnancy (28). Uterine artery ligation clearly decreased uterine blood flow and caused fetal weight reduction (29), which resulted in neuronal cell death (30). Further, impaired neuronal cell bodies were observed in the hippocampus and cerebral cortex (31), and were reduced in the entorhinal cortex (32). Hypoxic injury, like uterine artery ligation, was also associated with oligodendrocyte maturation (33) and defects in myelination (34). These deficits were related with neurobehavioral problems, including motor hyperactivity, posture abnormalities, and working memory deficit $(35,36)$.

In the current study, immunoreactivity was observed in two regions: the SVZ and cerebral parietal cortex. The SVZ is a neurogenic zone that responds to hypoxic injury during the late stage of brain development (37). This area is associated with neuronal cell proliferation (38). The parietal cortex is more vulnerable to insult than other cortices. For example, although the primary motor cortex in rats with placental insufficiency did not show neuronal density reduction (11), the parietal cortex in rats with a similar condition showed structural abnormality (39). Finally, neuronal survival in the cerebral cortex of fetuses has been previously associated with the ERK pathway (40).

In the current study, we used a PCNA antibody to determine cell proliferation in the SVZ, since it is a nuclear protein since it is an essential element that binds polymerased during leading-strand DNA synthesis (41). PCNA expression appears during the $\mathrm{G}_{1}$ phase and is maximal during the $S$ phase (42). Although the density of PCNA-IR cells in the GR group was a little lower than in the control group, this difference was not statistically significant. Previous studies indicate the reduction of neural progenitor cells after hypoxic damage and the presence of immature neuronal cells or apoptotic cells $(38,43)$. Tolcos et al. (27) found that although cell proliferation increased, the weight of the brain was decreased. These results suggest the variability of the intrauterine micro-environment.

Next, we used NeuN antibody to determine the density of mature neurons in the cerebral parietal cortex. NeuN is a monoclonal antibody, and its nuclear antigen is detected during neurogenesis progress and is restricted to neurons (44). The density of NeuN-IR cells in the cerebral parietal 

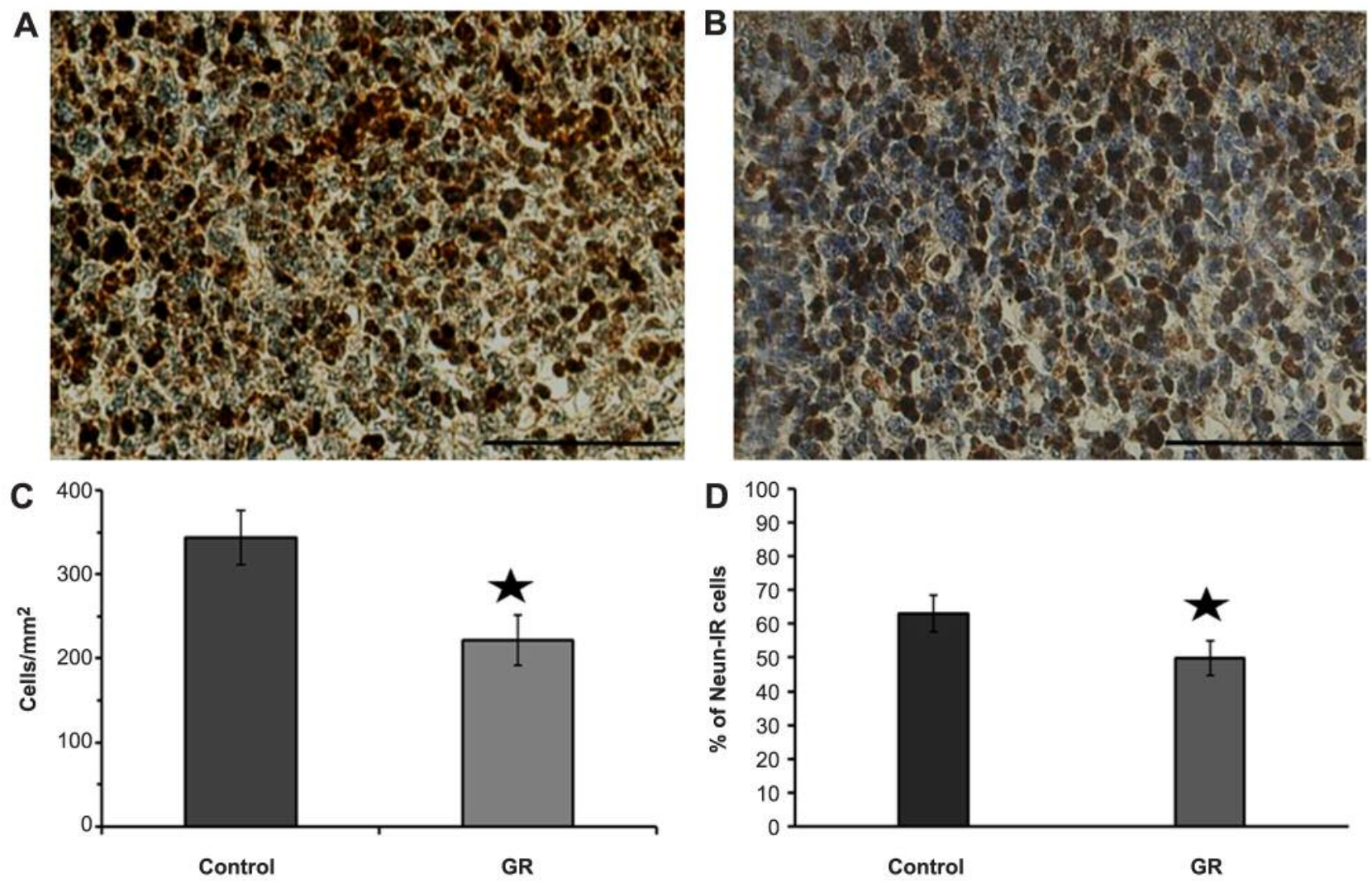

Figure 2. Representative photomicrographs of NeuN-IR cells in the granular layer of the l parietal cortex. NeuN-IR cells (dark-brown color) were scattered in both the control $(A)$ and GR (B) groups. Scale bars $=100 \mu \mathrm{m}$. The density (C) and proportion (D) of NeuN-IR cells in the cerebral parietal cortex of control and GR fetuses at 21 days of gestation. The density and proportion of IR cells was lower in the GR group than in the control group. Values are expressed as the mean \pm SEM. $* p<0.05$.

cortex decreased in the GR group. This result was similar to our previous study, using a guinea pig model that showed chronic placental insufficiency $(21,45)$. Similarly, the density of NeuN-IR cells was significantly reduced in the developing chick brain (46). These results suggest that the survival of neurons in the cerebral cortex was reduced in GR fetuses.

ERK $1 / 2$ are members of the mitogen-activated protein kinase (MAPK) family (47), which elicits an intracellular signaling cascade, i.e., the Ras-Raf-MEK-ERK signaling pathway, which is involved in the development of neurons (48). Activation of the ERK pathway was modulated by extracellular stimuli, and affected cell proliferation and differentiation (49). In the current study, the density of pERK in the SVZ was the same between control and GR groups. Since the neuronal cell loss in IUGR is normalized after a few years, it is possible that the ERK pathway triggers neural progenitor cell differentiation into neural cells (50). Therefore, simply increasing the activation ERK in an attempt to compensate for hypoxic damage is not enough. The density of pERK and mature neuronal survival was reduced in the cerebral parietal cortex in the GR group, in comparison to the control. Since the activation of ERK by phosphorylation promoted cell survival in cortical neurons (23), we suggest that the reduction of pERK immunoreactivity is associated with the decreased neuronal survival in the cerebral cortex. Neurotrophin factors protected cortical neurons by ERK activation (51). ERK activation has effects on early human neurogenesis (52) and cancer clinicopathologic (53). So, the results about ERK phosphorylation are associated with therapeutic window (54). There are two representative protection mechanisms that are elicited by ERK-activated BDNF, the inhibition of pro-apoptotic proteins (55) and the induction of CRE-binding protein phosphorylation (56).

\section{Conclusion}

IUGR induced by uterine artery ligation leads to reduction of neuronal survival in the cerebral parietal cortex, but not to the reduction of proliferation in SVZ. In the cerebral cortex, the reduction in neuronal survival is associated with the decrease of cells expressing pERK. 

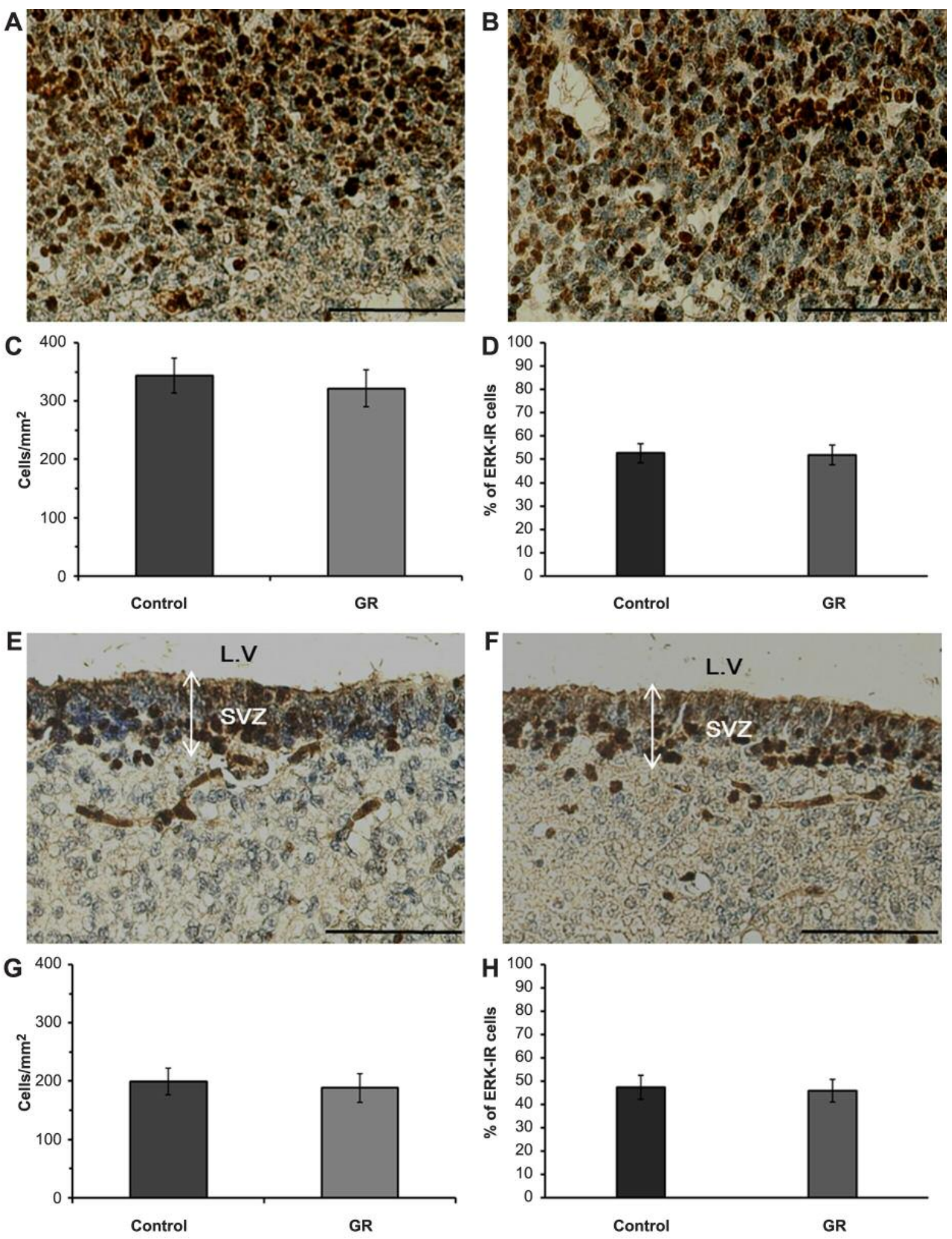

Figure 3. Representative images of ERK-IR cells (dark-brown) in the cerebral parietal cortex (A: control B: GR) and SVZ (E: control F: GR) at 21 days of gestation. Scale bars=100 um. The density (C: cerebral cortex G: SVZ) and proportion (D: cerebral cortex H: SVZ) of ERK-IR cells in the control and GR groups at 21 days of gestation. No significant differences in the density and proportion of ERK-IR cells in the cerebral parietal cortex and SVZ were observed between the two groups. 

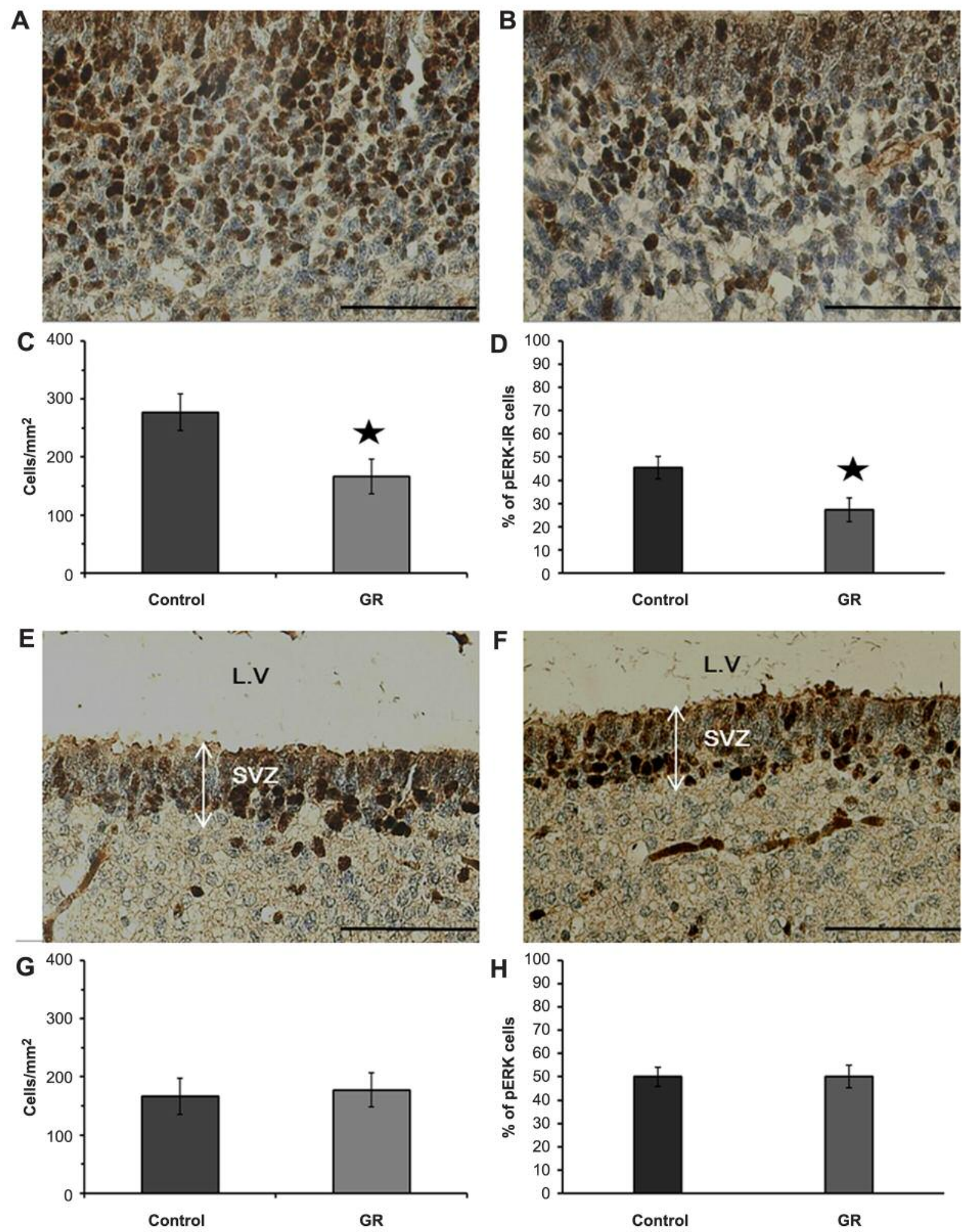

Figure 4. Analysis of pERK-IR cells (dark-brown) in the cerebral parietal cortex (A: control B: GR) and SVZ (E: control F: GR) at 21 days of gestation. Scale bars $=100 \mu \mathrm{m}$. The density (C: cerebral cortex $G$ : SVZ) and proportion (D: cerebral cortex H: SVZ) of pERK-IR cells in the control and GR groups at 21 days of gestation. The density and proportion of pERK-IR cells were decreased in the cerebral parietal cortex of GR fetuses, relative to those of controls. Values are expressed as the mean $\pm S E M .{ }^{*} p<0.05$. 


\section{Conflicts of Interest}

The Authors declare that no competing interests exist.

\section{Authors' Contributions}

JYH designed the study. KST participated in the surgical procedures. KDJ analyzed the obtained data. CYY and CMS performed the immunohistochemistry. All Authors read and approved the final manuscript.

\section{Acknowledgements}

This study was supported by research funds from Chosun University (2015).

\section{References}

1 Alfirevic Z and Neilson JP: Doppler ultrasonography in highrisk pregnancies: Systematic review with meta-analysis. Am J Obstet Gynecol 172(5): 1379-1387, 1995. PMID: 7755042. DOI: 10.1016/0002-9378(95)90466-2

2 McIntire DD, Bloom SL, Casey BM and Leveno KJ: Birth weight in relation to morbidity and mortality among newborn infants. N Engl J Med 340(16): 1234-1238, 1999. PMID: 10210706. DOI: $10.1056 /$ nejm199904223401603

3 Fung C, Ke X, Brown AS, Yu X, McKnight RA and Lane RH: Uteroplacental insufficiency alters rat hippocampal cellular phenotype in conjunction with erbb receptor expression. Pediatr Res 72(1): 2-9, 2012. PMID: 22367251. DOI: 10.1038/pr.2012.32

4 Mari G: Doppler ultrasonography in obstetrics: From the diagnosis of fetal anemia to the treatment of intrauterine growthrestricted fetuses. Am J Obstet Gynecol 200(6): 611-619, 2009. PMID: 19200940. DOI: 10.1016/j.ajog.2008.10.054

5 Morrison JL: Sheep models of intrauterine growth restriction: Fetal adaptations and consequences. Clin Exp Pharmacol Physiol 35(7): 730-743, 2008. PMID: 18498533. DOI: 10.1111/j.14401681.2008.04975.x

6 Reid MV, Murray KA, Marsh ED, Golden JA, Simmons RA and Grinspan JB: Delayed myelination in an intrauterine growth retardation model is mediated by oxidative stress upregulating bone morphogenetic protein 4. J Neuropathol Exp Neurol 71(7): 640-653, 2012. PMID: 22710965. DOI: 10.1097/NEN $0 \mathrm{~b} 013 \mathrm{e} 31825 \mathrm{cfa} 81$

7 Mandruzzato G, Antsaklis A, Botet F, Chervenak FA, Figueras F, Grunebaum A, Puerto B, Skupski D and Stanojevic M: Intrauterine restriction (iugr). J Perinat Med 36(4): 277-281, 2008. PMID: 18598115. DOI: 10.1515/jpm.2008.050

8 Wadley GD, McConell GK, Goodman CA, Siebel AL, Westcott KT and Wlodek ME: Growth restriction in the rat alters expression of metabolic genes during postnatal cardiac development in a sex-specific manner. Physiol Genomics 45(3): 99-105, 2013. PMID: 23232075. DOI: 10.1152/physiolgenomics 00095.2012

9 Tare M, Parkington HC, Bubb KJ and Wlodek ME: Uteroplacental insufficiency and lactational environment separately influence arterial stiffness and vascular function in adult male rats. Hypertension 60(2): 378-386, 2012. PMID: 22733472. DOI: 10.1161/HYPERTENSIONAHA.112.190876
10 Delcour M, Russier M, Amin M, Baud O, Paban V, Barbe MF and Coq JO: Impact of prenatal ischemia on behavior, cognitive abilities and neuroanatomy in adult rats with white matter damage. Behav Brain Res 232(1): 233-244, 2012. PMID: 22521835. DOI: 10.1016/j.bbr.2012.03.029

11 Delcour M, Olivier P, Chambon C, Pansiot J and Russier M: Neuroanatomical, sensorimotor and cognitive deficits in adult rats with white matter injury following prenatal ischemia. Brain Pathol 22(1): 1-16, 2012. PMID: 21615591. DOI: 10.1111/ j.1750-3639.2011.00504.x

12 Karlberg J, Jalil F, Lam B, Low L and Yeung CY: Linear growth retardation in relation to the three phases of growth. Eur J Clin Nutr 48: 25-43, 1994. PMID: 8005089.

13 Dimeglio A: Growth in pediatric orthopaedics. J Pediatr Orthop 21(4): 549-555, 2001. PMID: 11433174.

14 Dahlseng MO, Andersen GL, Irgens LM, Skranes J and Vik T: Risk of cerebral palsy in term-born singletons according to growth status at birth. Dev Med Child Neurol 56(1): 53-58, 2014. PMID: 24117018. DOI: 10.1111/dmen.12293

15 Van L, Butcher NJ, Costain G, Ogura L, Chow EW and Bassett AS: Fetal growth and gestational factors as predictors of schizophrenia in 22q11.2 deletion syndrome. Genet Med 18(4): 350-355, 2016. PMID: 26087175. DOI: 10.1038/gim.2015.84

16 Dringenberg HC, Richardson DP, Brien JF and Reynolds JN: Spatial learning in the guinea pig: Cued versus non-cued learning, sex differences, and comparison with rats. Behav Brain Res 124(1): 97-101, 2001. PMID: 11423170. DOI: 10.1016/ s0166-4328(01)00188-7

17 Chung Y, Cho H, Jo GH and Jun Y: Hypoxia of rats subjected to carotid artery ligation results in impaired neurogenesis and reduced number of cortical neurons. In Vivo 33(2): 441-445, 2019. PMID: 30804123. DOI: 10.21873/invivo.11492

18 So K, Chung Y, Yu SK and Jun Y: Regional immunoreactivity of pax6 in the neurogenic zone after chronic prenatal hypoxia. In Vivo 31(6): 1125-1129, 2017. PMID: 29102934. DOI: 10.21873/invivo.11178

19 Dieni S and Rees S: Dendritic morphology is altered in hippocampal neurons following prenatal compromise. J Neurobiol 55(1): 41-52, 2003. PMID: 12605458. DOI: 10.1002/neu.10194

20 Tolcos M, Bateman E, O'Dowd R, Markwick R, Vrijsen K, Rehn A and Rees S: Intrauterine growth restriction affects the maturation of myelin. Exp Neurol 232(1): 53-65, 2011. PMID: 21867703. DOI: 10.1016/j.expneurol.2011.08.002

21 Chung Y, So K, Kim E, Kim S and Jeon Y: Immunoreactivity of neurogenic factor in the guinea pig brain after prenatal hypoxia. Ann Anat 200: 66-72, 2015. PMID: 25794637. DOI: 10.1016/ j.aanat.2015.02.003

22 Wang H, Chung Y, Yu SK and Jun Y: The immunoreactivity of pi3k/akt pathway after prenatal hypoxic damage. In Vivo 31(5): 855-860, 2017. PMID: 28882951. DOI: 10.21873/invivo.11139

23 Sun X, Zhou H, Luo X, Li S, Yu D, Hua J, Mu D and Mao M: Neuroprotection of brain-derived neurotrophic factor against hypoxic injury in vitro requires activation of extracellular signalregulated kinase and phosphatidylinositol 3-kinase. Int J Dev Neurosci 26(3-4): 363-370, 2008. PMID: 18243629. DOI: 10.1016/j.ijdevneu.2007.11.005

24 Xia Z, Dickens M, Raingeaud J, Davis RJ and Greenberg ME: Opposing effects of erk and jnk-p38 map kinases on apoptosis. Science 270(5240): 1326-1331, 1995. PMID: 7481820. DOI: $10.1126 /$ science. 270.5240 .1326 
25 Meyer-Franke A, Wilkinson GA, Kruttgen A, Hu M, Munro E, Hanson MG, Jr., Reichardt LF and Barres BA: Depolarization and camp elevation rapidly recruit trkb to the plasma membrane of cns neurons. Neuron 21(4): 681-693, 1998. PMID: 9808456. DOI: 10.1016/s0896-6273(00)80586-3

26 Inaloz HS, Sari I, Inaloz SS, Bayhan G and Yuncu M: Effects of unilateral uterine artery ligation on skin development. Clin Exp Obstet Gynecol 27(3): 218-220, 2000. PMID: 11214956.

27 Tolcos M, Markwick R, O’Dowd R, Martin V, Turnley A and Rees S: Intrauterine growth restriction: Effects on neural precursor cell proliferation and angiogenesis in the foetal subventricular zone. Dev Neurosci 37(4-5): 453-463, 2015. PMID: 25720426. DOI: 10.1159/000371344

28 Wigglesworth JS: Experimental growth retardation in the foetal rat. J Pathol Bacteriol 88: 1-13, 1964. PMID: 14194979.

29 Gilbert $\mathrm{M}$ and Leturque A: Fetal weight and its relationship to placental blood flow and placental weight in experimental intrauterine growth retardation in the rat. J Dev Physiol 4(4): 237-246, 1982. PMID: 7175121.

30 Basilious A, Yager J and Fehlings MG: Neurological outcomes of animal models of uterine artery ligation and relevance to human intrauterine growth restriction: A systematic review. Dev Med Child Neurol 57(5): 420-430, 2015. PMID: 25330710. DOI: $10.1111 / \mathrm{dmcn} .12599$

31 Ohshima M, Coq JO, Otani K, Hattori Y, Ogawa Y, Sato Y, Harada-Shiba $\mathbf{M}$, Ihara $\mathbf{M}$ and Tsuji $\mathbf{M}$ : Mild intrauterine hypoperfusion reproduces neurodevelopmental disorders observed in prematurity. Sci Rep 6(3): 9377, 2016. PMID: 27996031. DOI: $10.1038 /$ srep39377

32 Coq JO, Delcour M, Massicotte VS, Baud O and Barbe MF: Prenatal ischemia deteriorates white matter, brain organization, and function: Implications for prematurity and cerebral palsy. Dev Med Child Neurol 58(4): 7-11, 2016. PMID: 27027601. DOI: $10.1111 / \mathrm{dmcn} .13040$

33 French HM, Reid M, Mamontov P, Simmons RA and Grinspan JB: Oxidative stress disrupts oligodendrocyte maturation. J Neurosci Res 87(14): 3076-3087, 2009. PMID: 19479983. DOI: $10.1002 /$ jnr.22139

34 Olivier P, Fontaine RH, Loron G, Van Steenwinckel J, Biran V, Massonneau V, Kaindl A, Dalous J, Charriaut-Marlangue C, Aigrot MS, Pansiot J, Verney C, Gressens $\mathrm{P}$ and Baud O: Melatonin promotes oligodendroglial maturation of injured white matter in neonatal rats. PLoS One 4(9): 7128, 2009. PMID: 19771167. DOI: 10.1371/journal.pone.0007128

35 Lawrence KE, Levitt JG, Loo SK, Ly R, Yee V, O’Neill J, Alger $\mathrm{J}$ and Narr KL: White matter microstructure in subjects with attention-deficit/hyperactivity disorder and their siblings. J Am Acad Child Adolesc Psychiatry 52(4): 431-440, 2013. PMID: 23582873. DOI: 10.1016/j.jaac.2013.01.010

36 Caprau D, Schober ME, Bass K, O'Grady S, Ke X, Block B, Callaway CW, Hale M, Yu X, McKnight RA, Kesner RP and Lane RH: Altered expression and chromatin structure of the hippocampal igf1r gene is associated with impaired hippocampal function in the adult iugr male rat. J Dev Orig Health Dis 3(2): 83-91, 2012. PMID: 25101918. DOI: 10.1017/s204017 4411000791

37 Kriegstein A and Alvarez-Buylla A: The glial nature of embryonic and adult neural stem cells. Annu Rev Neurosci 32: 149-184, 2009. PMID: 19555289. DOI: 10.1146/annurev.neuro. 051508.135600
38 Spadafora R, Gonzalez FF, Derugin N, Wendland M, Ferriero D and McQuillen P: Altered fate of subventricular zone progenitor cells and reduced neurogenesis following neonatal stroke. Dev Neurosci 32(2): 101-113, 2010. PMID: 20453463. DOI: $10.1159 / 000279654$

39 Tashima L, Nakata M, Anno K, Sugino N and Kato H: Prenatal influence of ischemia-hypoxia-induced intrauterine growth retardation on brain development and behavioral activity in rats. Biol Neonate 80(1): 81-87, 2001. PMID: 11474155. DOI: $10.1159 / 000047125$

40 Bonni A, Brunet A, West AE, Datta SR, Takasu MA and Greenberg ME: Cell survival promoted by the ras-mapk signaling pathway by transcription-dependent and -independent mechanisms. Science 286(5443): 1358-1362, 1999. PMID: 10558990. DOI: $10.1126 /$ science.286.5443.1358

41 Fairman MP: DNA polymerase delta/pcna: Actions and interactions. J Cell Sci 95(1): 1-4, 1990. PMID: 1972157.

42 Candal E, Anadon R, DeGrip WJ and Rodriguez-Moldes I: Patterns of cell proliferation and cell death in the developing retina and optic tectum of the brown trout. Brain Res Dev Brain Res 154(1): 101-119, 2005. PMID: 15617760. DOI: 10.1016/j.devbrainres.2004.10.008

43 Levison SW, Rothstein RP, Romanko MJ, Snyder MJ, Meyers RL and Vannucci SJ: Hypoxia/ischemia depletes the rat perinatal subventricular zone of oligodendrocyte progenitors and neural stem cells. Dev Neurosci 23(3): 234-247, 2001. PMID: 11598326. DOI: $10.1159 / 000046149$

44 Mullen RJ, Buck CR and Smith AM: Neun, a neuronal specific nuclear protein in vertebrates. Development 116(1): 201-211, 1992. PMID: 14833388.

45 So K, Chung Y, Lee H, Kim E and Jeon Y: The effect of chronic prenatal hypoxia on the development of mature neurons in the cerebellum. J Neurodev Disord 5(1): 17, 2013. PMID: 23822215. DOI: $10.1186 / 1866-1955-5-17$

46 Rodricks CL, Gibbs ME, Castillo-Melendez M and Miller SL: The effect of hypoxia on the functional and structural development of the chick brain. Int J Dev Neurosci 28(4): 343350, 2010. PMID: 20171268. DOI: 10.1016/j.ijdevneu. 2010.02 .004

47 Roskoski R, Jr.: Erk1/2 map kinases: Structure, function, and regulation. Pharmacol Res 66(2): 105-143, 2012. PMID: 22569528. DOI: $10.1016 /$ j.phrs.2012.04.005

48 Zsarnovszky A and Belcher SM: Spatial, temporal, and cellular distribution of the activated extracellular signal regulated kinases 1 and 2 in the developing and mature rat cerebellum. Brain Res Dev Brain Res 150(2): 199-209, 2004. PMID: 15158083. DOI: 10.1016/j.devbrainres.2004.03.012

49 Uko NE, Guner OF, Bowen JP and Matesic DF: Akt pathway inhibition of the solenopsin analog, 2-dodecylsulfanyl-1,-4,-5,6-tetrahydropyrimidine. Anticancer Res 39(10): 5329-5338, 2019. PMID: 31570426. DOI: 10.21873/anticanres.13725

50 Moors M, Cline JE, Abel J and Fritsche E: Erk-dependent and independent pathways trigger human neural progenitor cell migration. Toxicol Appl Pharmacol 221(1): 57-67, 2007. PMID: 17445854. DOI: $10.1016 /$ j.taap .2007.02.018

51 Hetman M, Kanning K, Cavanaugh JE and Xia Z: Neuroprotection by brain-derived neurotrophic factor is mediated by extracellular signal-regulated kinase and phosphatidylinositol 3-kinase. J Biol Chem 274(32): 2256922580, 1999. PMID: 10428835. DOI: 10.1074/jbc.274.32.22569 
52 Mellios N, Feldman DA, Sheridan SD, Ip JPK, Kwok S, Amoah SK, Rosen B, Rodriguez BA, Crawford B, Swaminathan R, Chou S, Li Y, Ziats M, Ernst C, Jaenisch R, Haggarty SJ and Sur M: Mecp2-regulated mirnas control early human neurogenesis through differential effects on erk and akt signaling. Mol Psychiatry 23(4): 1051-1065, 2018. PMID: 28439102. DOI: $10.1038 / \mathrm{mp} .2017 .86$

$53 \mathrm{Kim}$ DH, Han SI, Go B, Oh UH, Kim CS, Jung YH, Lee J and Kim JH: 2-methoxy-4-vinylphenol attenuates migration of human pancreatic cancer cells via blockade of fak and akt signaling. Anticancer Res 39(12): 6685-6691, 2019. PMID: 31810933. DOI: 10.21873/anticanres.13883

54 Bhushan L, Tavitian N, Dey D, Tumur Z, Parsa C and Kandpal RP: Modulation of liver-intestine cadherin (cadherin 17) expression, erk phosphorylation and wnt signaling in ephb6 receptor-expressing mda-mb-231 cells. Cancer Genomics Proteomics 11(5): 239-249, 2014. PMID: 25331796.
55 Kurada P and White K: Ras promotes cell survival in drosophila by downregulating hid expression. Cell 95(3): 319-329, 1998. PMID: 9814703. DOI: 10.1016/s0092-8674(00)81764-x

56 Moosavi F, Hosseini R, Saso L and Firuzi O: Modulation of neurotrophic signaling pathways by polyphenols. Drug Des Devel Ther 10: 23-42, 2016. PMID: 26730179. DOI: 10.2147/ dddt.s96936
Received December 10, 2019

Revised December 21, 2019

Accepted January 5, 2020 